\title{
ПРЕВЕНТИВНАЯ ЗАЩИТА ОТ РЕЙДЕРСКИХ АТАК
}

\begin{abstract}
Аннотация: В настоящей статье, составленной на основе реферата, подготовленного по итогам обучения на факультативе по курсу “Безопасность предпринимательской деятельности», рассматривается актуальная для современной России тема рейдерских захватов. Представлены направления работы по построению превентивной системы безопасности компании, а также указаны способы защиты от рейдерских атак. Приводятся примеры из практики осуществления рейдерских захватов.
\end{abstract}

Ключевые слова: Юриспрудениия, рейдерство, безопасность, захват, атака, защита, предприятие, акиионеры, кредиторская задолженность, превентивные меры

\section{Введение}

T ермин «рейдер» существует довольно давно. Первоначально так назывались военные суда, которые уничтожали торговые и транспортные суда неприятеля, сегодня под этим термином понимается совсем иное значение. В современной России термин «рейдер» не имеет своего точного законодательного закрепления, однако, обобщив различные трактовки и понятия этого явления в юридической литературе, этот термин следует понимать как общественно опасное, противоправное деяние, связанное с незаконным приобретением права владения, и (или) пользования, и (или) распоряжения активами (частью активов) юридического лица, либо связанное с установлением контроля над юридическим лицом путем незаконного приобретения права владения, и (или) пользования, и (или) распоряжения долями участников юридического лица в уставном капитале юридического лица и (или) голосующими акциями акционерного общества, причиняющее вред правам и законным интересам собственников и осуществляемое вопреки их волеизъявлению, угрожающее безопасности личности, общества и государства. ${ }^{1}$

По данным газеты «Известия» в 2010 году было зарегистрировано чуть более 30 экономических преступлений, связанных с рейдерством, а в 2011 году - 77. За первое полугодие 2012 года было зарегистрировано 52 подобных преступления. Всего в МВД расследуется 150 уголовных дел против рейдеров.

В Следственном комитете рост рейдерства связывают со вступлением в силу в июле 2010 года поправок в УК, уточняющих понятие рейдерства и

${ }^{1}$ Фёдоров А.Ю., Рейдерство и корпоративный шантаж (организационно-правовые меры противодействия), М.,2010, Волтерс Клувер. ужесточающих наказание за подобные преступления. Если раньше МВД возбуждало против рейдеров уголовные дела лишь по статье «мошенничество» и «подделка документов», то теперь рейдеров можно привлекать к ответственности за подачу в налоговую инспекцию ложных данных об учредителях, за подделку решений общего собрания акционеров и совета директоров, за фальсификацию реестров и результатов голосования. ${ }^{2}$

Рейдерство в России связано с такими угрозами экономической безопасности, как увеличение коррумпированности государственных служащих и представителей судейского корпуса, повышение уровня безработицы, уклонение от уплаты налогов, монополизация ряда сегментов рынка, утрата конкурентоспособности, разрушение и спад производства, дискредитация представителей федеральной и региональной власти, правоохранительных органов и судов, ухудшение инвестиционного климата, деформация правовой идеологии и распространение правового нигилизма, активизация процессов отмывания денег, полученных преступным путем. Следовательно, противодействие рейдерству имеет не только правовое, но и политическое значение.

\section{Построение превентивной системы защиты от рейдерских атак}

Совершенно очевидно, что предотвращать угрозы всегда проще, чем бороться с ними. Как показывает практика, борьба в условиях уже начавшегося захвата редко бывает эффективной и сопряжена со значительными издержками. Однако, не смотря на эту простую истину, система превентивной безопасности в России остаётся недооцененной. Отече-

2 http://izvestia.ru/news/521674. 


\section{Национальная безопасность $1(24) \cdot 2013$}

ственные предприниматели очень часто пренебрегают этими мерами в силу их высокой стоимости или же в силу халатного отношения к потенциальным угрозам безопасности.

Как правило, руководство компаний обращается к специалистам по безопасности, когда нападение уже совершено, то есть реагируют на угрозы только после их обнаружения. Обычно, в этом случае уже поздно разрабатывать систему безопасности на предприятии, и количество мер, которые возможно применить для предотвращения враждебного поглощения, значительно сокращается.

Между тем, многие угрозы враждебных слияний и поглощений можно было бы предотвратить, выстроив эффективную систему превентивных мер, направленных на защиту предприятия. Павел Астахов, предлагает выстраивать такую систему по следующим направлениям: ${ }^{3}$

1) проведение постоянного мониторинга внешнего информационного поля с целью своевременного обнаружения признаков угроз недружественного поглощения;

2) построение надежной системы защиты инсайдерской информации;

3) разработка и внесение изменений в учредительные и иные документы компании, направленные на минимизацию возможностей агрессора по перехвату корпоративного контроля;

4) проведение политики, способствующей проявлению у наемных менеджеров-управленцев мотивации на развитие бизнеса;

5) постоянная работа с акционерами;

6) осуществление управления кредиторской задолженностью;

7) внедрение механизмов, призванных защитить владельцев от утраты акций/долей, а также от их хищения;

8) реализация схем по защите активов компании.

А.Ю. Фёдоров дополняет этот список ещё двумя направлениями: ${ }^{4}$

9) создание эффективной корпоративной структуры в целях распределения финансовых и операционных рисков;

10) формирование внутренней службы безопасности.

Рассмотрим каждое из этих направлений подробнее.

\footnotetext{
${ }^{3}$ Астахов П.А., Противодействие рейдерским захватам, М., 2008, Эксмо.

4 Фёдоров А.Ю., Рейдерство и корпоративный шантаж (организационно-правовые меры противодействия),М., 2010 , Волтерс Клувер.
}

\section{1. Постоянный сбор и анализ внешней информации.}

Предупреждён - значит, вооружён, гласит древняя мудрость. Наличие заранее поступившей информации о готовящемся захвате позволит заблаговременно подготовиться к отражению рейдерской атаки. Своеобразными индикаторами, позволяющими говорить о начавшейся подготовке рейдерского захвата, служат:

1) Внезапная активность миноритарных акционеров; «обычно миноритарные акционеры достаточно индифферентны к текущей деятельности компании, и если позиция одного из них или группы радикально изменилась, они стали проявлять ничем не обусловленный (и не наблюдавшийся ранее) интерес к деятельности предприятия и требуют предоставления копий различных документов, вероятнее всего, есть повод для опасения». 5

2) Прямые предложения о продаже акций или долей в уставном капитале от инвестиционных компаний.

3) Проявление ни чем не обусловленного интереса к компании у СМИ; получает распространение негативная информация о компании (злоупотребление свои положением руководства, нарушение прав акционеров, невыполнение компанией своих обязательств и т.д.).

4) Инициирование неожиданных судебных дел в отношении компании.

Инициирование судебных дел позволяет на законных основаниях (п. 2 ст. 57 ГПК РФ, п. 4 ст. 66 АПК РФ) истребовать через суд информацию и документы компании. «Использование судебных органов для легализации криминальных манипуляций представляет собой изобретение российской организованной экономической преступности. Такой прием используется в реализации сложных схем завладения чужой собственностью, в которых судебное решение легализует фальсифицированные документы. В дальнейшем на основании судебного решения происходит силовой захват предприятия» ${ }^{6}$.

5) Активизация проверок, проводимых контрольно-ревизионными и правоохранительными органами. Заказной характер таких проверок

\footnotetext{
${ }_{5}^{5}$ Фаенсон М.И., Пиманова А.А., Рейдерство (недружественный захват предприятий): практика современной России, М., 2007. C. 37

${ }^{6}$ Клейменов М.П., Федоров А.Ю. Криминальное манипулирование в сфере экономической деятельности: криминологическая характеристика и предупреждение: монография. С. 91.
} 
определяется требованиями предоставления копий документов об активах компании и её кредиторской задолженности.

6) Возникновение проблем в работе с контрагентами. Это может проявляться в отказе контрагентов работать без предоплаты, трудности с получением кредитов и т.д.

7) Получение органом управления заказного письма с чистым бланком. Данная схема применяется для имитации соблюдения формальных требований закона. К сожалению, российское законодательство позволяет представлять в суд в качестве доказательства почтовую квитанцию без уведомления о вручении письма получателю. Таким образом, это помогает захватчикам доказывать факты направления предложений о выкупе акций или требований о созыве внеочередного собрания.

\section{2. Формирование надежной системы защиты инсайдерской информации.}

Система защиты инсайдерской информации включает в себя:

- создание перечня документов, составляющих коммерческую тайну или представляющих повышенную важность для компании;

- выделение специальных особо, надежных мест, предназначенных для хранения подлинников правоустанавливающих документов компании и наиболее важной договорной базы;

- создание надёжных условий хранения внутренней документации компании в местах, недоступных для захватчика;

- создание строгого и контролируемого внутреннего порядка обращения с документацией и предоставления информации третьим лицам;

- создание качественной системы безопасности в IT-сфере;

- передаче бухгалтерских функций отдельной подконтрольной фирме (однако, отечественная практика показывает, что в отличие от развитых западных стран, эта тактика не всегда срабатывает; российские рейдеры могут начать осуществлять захват и с подконтрольной компании).

\section{3. Работа с учредительными и иными документами компании.}

Любые пробелы и противоречия устава являются потенциальной отправной точкой для осуществления рейдерского захвата, поэтому необходимо провести проверку и устранить недостатки учредительных документов, таких как противоречия действующему законодательству и несоответствие между собой.

Основное внимание при проведении анализа необходимо обратить на те положения, которые больше всего интересуют захватчиков, по мнению А.Ю. Фёдорова, к ним относятся:

- процедура проведения и принятия решений на внеочередном собрании акционеров (участников);

- положение об объявленных акциях, которое необходимо в соответствии с Федеральным законом «Об акционерных обществах» для принятия решения об увеличении уставного капитала общества путем размещения дополнительных акций;

- полномочия исполнительного органа;

- определение кворума общего собрания или совета директоров по вопросам, относящимся к их исключительной компетенции;

- процедура внесения изменений в учредительные документы;

- порядок уведомления акционеров о проведении общего собрания.?

\section{4. Проведение политики, способствующей} проявлению у наемных менеджеров-управленцев мотивации на развитие бизнеса.

В последнее время, в России складывается тенденция передачи ведения дел компании наёмному топ-менеджеру. В связи с этим, для успешного проведения рейдерской атаки в такой компании, зачастую становится достаточным прийти к соглашению с одним из таких топ-менеджеров. Для того чтобы исключить подобный вариант развития, собственники предприятия должны обеспечить заинтересованность у топ-менеджемента к добросовестному исполнению своих обязанностей и успешного развития компании. Этого можно добиться с помощью определения чётких границ полномочий наёмных менеджеров, установление высокой заработной платы, получение менеджерами бонусов от прибыли и т.п.

В качестве примера можно привести следующий случай:

В 2006 году бывший директор ФГУП «Казанский протезно-ортопедический завод» Владимир Урусов,

\footnotetext{
7 Фёдоров А.Ю., Рейдерство и корпоративный шантаж (организационно-правовые меры противодействия), М., 2010, Волтерс Клувер.
} 


\section{Национальная безопасность $1(24) \cdot 2013$}

бессменно руководивший предприятием в течение 14 лет, предстал перед Советским районным судом Казани по обвинению в том, что умышленно «в пользу третьих лиц» увеличивал неплатежеспособность завода. По версии следствия, согласно плану Урусова, к концу 2004 года задолженность предприятия перед кредиторами должна была составить около 20 млн. рублей. После чего завод должны были объявить банкротом. При этом по оперативным данным, автором плана был вовсе не Урусов и в действительности речь идет о хорошо организованной рейдерской атаке на завод. В обвинительном заключении были приведены конкретные факты незаконных действий менеджера, которые ярко описывают механизм рейдерства. Вначале, в январе 2004 года директор без ведома собственников (Министерство здравоохранения, а позже Росздрав) под залог оборотных средств получил в Татэкобанке кредит на 8 млн. рублей. Формальным поводом послужило отсутствие средств на расчетном счету завода. Однако в действительности никакой необходимости в кредите предприятие не испытывало. У завода было незавершенное производство, оценивавшееся в 7,3 млн. рублей. Также Минсоцзащиты задолжало предприятию еще 9,6 млн. рублей. В результате ненужной финансовой операции заводу был нанесен ущерб в 1,7 млн. рублей - за счет процентов за пользование кредитом. Через месяц во время проведения тендера Министерства социальной защиты по закупке протезно-ортопедической продукции завод подал заведомо неперспективную заявку. Кроме того, прокуроры привели еще ряд аналогичных примеров деяний бывшего директора, который, однако, свою вину не признал, заявляя, что руководствовался благими намерениями.

В результате, Советский райсуд признал Урусова виновным, но лишь в попытке преднамеренного банкротства. Еще по одиннадцати эпизодам обвинения его оправдали и приговорили к двум годам условного лишения свободы. После обжалования приговора Верховный суд Татарстана отменил его, но и следующий процесс закончился осуждением Урусова, вновь приговоренного в апреле 2007 года к двум годам условного лишения свободы, но не за попытку преднамеренного банкротства, а за превышении должностных полномочий. Впрочем, в связи с амнистией, приуроченной к 100-летию Думы, Урусов был освобожден от наказания. ${ }^{8}$

\footnotetext{
8 По материалам Центра политических технологий (http://www.politcom.ru/6210.html).
}

Этот случай убедительно доказывает, что наёмных менеджеров также необходимо контролировать. Одним из удачных поводов для этого могут служить ревизия и внешний аудит перед годовым собранием акционеров.

\section{5. Работа с акционерами.}

Как показывает практика, очень часто, именно миноритарные акционеры образуют брешь в системе защиты компании. Поэтому работа с ними, направленная на повышение заинтересованности акционеров в действующем руководстве компании, должна проводиться непрерывно.

Прежде всего, необходимо предоставление информации для акционеров должно происходить в таком ключе, который будет подчёркивать ценность компании для них. Отчетность, содержащую такую информацию, необходимо регулярно обновлять и предоставлять вниманию акционеров через бюллетень, собственную газету, корпоративный сайт и т.д. Иногда акционерам важны не только и не столько сами акции, сколько возможности, связанные с участием в акционерном обществе. Так, некоторые общества предоставляют акционерам бесплатные медицинские страховки, выдают небольшие ссуды и т.п. В такой ситуации акционерам становится психологически тяжело продавать акции.

Тем не менее, крупные компании (такие как Газпром или Сбербанк) на практике не принимают в расчёт интересы всех своих акционеров, учитываются интересы только тех акционеров, которые потенциально могут представлять для них угрозу.

Характерным примером может служить история Новосибирского авиаремонтного завода (НАРЗ). Неэффективное управление предприятием довело его до предбанкротного состояния. Весной 2005 года московская фирма «БФ-Медиа» (представляла интересы Русской вертолетной компании) начала скупку акций НАРЗа у миноритарных акционеров. Параллельно этот же процесс запустили ОАО «Новосибирскгражданпроект» и ЗАО «Русфинтех». В результате, РВК смогла консолидировать более $75 \%$ акций, то «Русфинтех»-11,67\%. По словам председателя совета директоров НАРЗа Юрия Андрианова, «представители «Русфинтеха» предложили нам выкупить их пакет по завышенной цене - 1,5 млн. долларов. После того, как мы ответили отказом, последовала череда судебных исков о признании недействительными решений собрания акционеров и выборов со- 
вета директоров. Все дела «Русфинтех» проиграл, но за это время часть своих акций продал офшорной панамской компании Myron Trade, после чего акционеры совместно стали обращаться в различные инстанции с заявлениями о выкупе предприятия, прекращении ремонта вертолетной техники и начале выпуска инвалидных колясок. НАРЗ пришлось доказывать, что предприятие ни при каких условиях не сменит своего профиля. В мае 2006 года Myron Trade вынесла на годовое собрание вопрос о ликвидации НАРЗа как акционерного общества - мажоритарные акционеры отклонили эту инициативу.

Затем атака на предприятие со стороны миноритариев остановилась. Видимо, это было связано с общей слабостью их позиций, а также с тем, что за время управления предприятием новой командой увеличился выпуск продукции и, как следствие, прибыли компании, что было выгодно и миноритарным акционерам. ${ }^{9}$

\section{6. Осуществление управления кредиторской задолженностью.}

Как показывает практика, наличие непогашенной кредиторской задолженности нередко становится отправной точкой для начала рейдерской атаки. Для обеспечения безопасности в этой области рекомендуется вести работу по следующим направлениям:

1) Первое и совершенно очевидное, это необходимо попытаться не допускать кредиторские задолженности, однако, по понятным причинам, это не всегда возможно. Поэтому необходимо выработать стратегию работы с кредиторами так, чтобы держать с ними постоянный контакт и дружеские отношения, во избежание обращения в судебные инстанции.

2) Необходимо тщательно подбирать контрагентов. Например, если в качестве контрагента выступает неизвестная или малоизвестная компания, которая настаивает на включении в договор пункта о подсудности споров арбитражным судам по месту нахождения истца, то, по мнению А.Ю. Фёдорова, можно с высокой долей вероятности утверждать, что эта компания напрямую связана с агрессором. В нужный момент она изменит свой расчетный счет и исчезнет, а затем будет сделано все возможное, чтобы отдаленный арбитражный суд признал компаниюцель банкротом и чтобы она узнала б этом только из

\footnotetext{
9 По материалам Центра политических технологий (http://www.politcom.ru/6210.html).
}

заявления о признании ее несостоятельной. Учитывая подобный вариант развития событий, очевидна целесообразность включения в договор положения, обязывающего контрагента предприятия сообщать об изменении своих реквизитов. Эта предосторожность позволяет в значительной степени осложнить процедуру банкротства с использованием схемы «временного исчезновения кредитора». ${ }^{10}$ Помимо этих мер предосторожности, сотрудники службы безопасности должны вести непрерывный мониторинг наиболее значимых кредиторов компании.

3) Разумным решением видится создание специальной подконтрольной компании, которая будет накапливать кредиторскую задолженность основной компании. Использование этой схемы даёт возможность аккумулировать всю нежелательную задолженность на другом юридическом лице. Наличие такой подконтрольной кредиторской задолженности может помочь, в случае банкротства, собственникам головной компании получить большинство на собрании кредиторов в процессе наблюдения, сформировать нужный совет кредиторов и избрать нужного внешнего управляющего.

Главной опасностью такого метода являются возможные подозрения кредиторов в попытке компании (заёмщика) уйти от исполнения обязательств по кредиту, поэтому реализовывать такую схему необходимо крайне осмотрительно, чтобы не вызывать ненужные подозрения у потенциальных кредиторов.

Когда накопление текущей кредиторской задолженности невозможно, используются различные схемы ее искусственного создания. Весьма популярна тактика создания финансовых «ядовитых пилюль» или так называемых фальшивых кредиторов. Компания-цель заключает договоры, по условиям которых должник несет крупные денежные обязательства перед дружественными ему компаниями. При проведении процедуры банкротства дружественные кредиторы лоббируют интересы должника. ${ }^{11}$

\section{7. Защита владельцев от утраты (хищения) акций.}

Основным способом контроля над компанией является наличие контрольного пакета акций, соответственно основной целью рейдеров станет завла-

\footnotetext{
${ }^{10}$ Фёдоров А.Ю. Рейдерство и корпоративный шантаж (организационно-правовые меры противодействия), М., 2010 , Волтерс Клувер

${ }^{11}$ Астахов П.А., Противодействие рейдерским захватам, М., 2007, Эксмо
} 


\section{Национальная безопасность 1(24) • 2013}

дение контрольным пакетом. Если акции распределены среди большого числа акционеров (например, на ранних стадиях приватизации такими акционерами являлись сами работники предприятия), то захватчик может начать массовую скупку акций для формирования контрольного пакета. В связи с этим очевидно, что в целях безопасности лучше всего самому являться обладателем контрольного пакета, однако это довольно капиталоёмкий процесс, поэтому не во всех ситуациях доступный. Однако существует несколько способов защиты компании и без обладания контрольным пакетом.

Одним из них является, так называемая, схема перекрёстного владения акциями. Суть этой схемы проста: головная компания создаёт дочернюю компанию, в которой владеет контрольным пакетом акций; остальными учредителями этой дочерней компании являются миноритарные акционеры головной компании, которые вносят вклад в уставный капитал дочерней компании своими акциями головной компании. Основная трудность в использовании этой схемы заключается в создании заинтересованности миноритарных акционеров вкладывать свои акции в уставный капитал дочерней компании. Таким образом, эта схема позволяет достигнуть двух целей ${ }^{12}$ :

1) у контролируемой дочерней компании консолидируется существенный пакет акций материнской компании, который в совокупности с акциями собственника бизнеса формирует желаемый контрольный пакет;

2) материнская компания в лице исполнительного органа может принимать «нужные» решения на общих собраниях акционеров (участников) дочерней компании по всем ключевым вопросам, а дочерняя компания в лице контролируемого генерального директора обеспечивает принятие таких же решений на общих собраниях головной компании.

Другим способом защиты акций выступает создание условий, исключающих возможность внесения незаконных изменений в записи по лицевым счетам в реестре акционеров. К сожалению, на текущий момент отсутствует законодательно закрепленная обязанность предоставлять реестродержателю одновременно с передаточным распоряжением на списание акций доказательства совершения сделки по отчуждению акций. Регистратор, получая передаточное распоряжение, не обязан досконально из-

12 Фёдоров А.Ю., Рейдерство и корпоративный шантаж (организационно-правовые меры противодействия, М., 2010, Волтерс Клувер. учать обстоятельства сделки, он лишь сверяет подпись и печать с хранящимися у него образцами. Поскольку предотвратить хищение акций можно лишь на этом этапе, значимость регистратора в системе превентивной безопасности становится очевидна. Хорошие отношения с его представителями могут оказать неоценимую помощь в случае, если компания-агрессор попытается похитить акции, предоставив реестродержателю поддельное передаточное распоряжение. В этот момент служба безопасности «компании-жертвы» обнаружит поддельные документы и свяжет их с конкретными лицами, а полиция (при наличии законных оснований) возбудит уголовное дело.

Среди других возможны варианты выстраивания отношений с реестродержателем. В юридической литературе предлагаются, например, такие ${ }^{13}$ :

1) включение в договор с реестродержателем обязанности информировать эмитента в течение суток обо всех случаях, когда производятся записи по лицевым счетам держателей контрольного пакета акций, связанные с отчуждением или обременением акций;

2) сотрудничество с регистратором, который страхует свою ответственность и готов в договоре с эмитентом указать, что он несет ответственность за убытки, причиненные акционерам или эмитенту в случае, если будет произведено списание акций со счета акционера по подложному передаточному распоряжению и т.д.;

\section{8. Защита активов компании.}

Понятие «защиты активов» в российской юридической практике явление относительно новое. Защита активов может осуществляться по разным направлениям, наиболее успешными представляются следующие из них.

Внедрение холдинговой структуры. Главный элемент подобной реструктуризации - выделение в компании владельческого, производственного, управленческого и торгового блоков бизнеса, когда данные функции выполняет не одна структура, а четыре самостоятельных юридических лица (так называемая схема четырех углов). При этом владельческая компания является собственником всех основных активов бизнеса и практически не участвует в текущей хозяйственной деятельности, что

\footnotetext{
${ }^{13}$ Добровольский В.И., Защита корпоративной собственности в арбитражном суде.
} 
значительно снижает риски возникновения неконтролируемой кредиторской задолженности, судебных споров и т.д. ${ }^{14}$

Обременение активов. Согласно ст. 1 Федерального закона от 21 июля 1997 г. N 122-Ф3 «О государственной регистрации прав на недвижимое имущество и сделок с ним» обременение недвижимого имущества - это наличие установленных законом или уполномоченными органами в предусмотренном законом порядке условий, запрещений, стесняющих правообладателя при осуществлении права собственности либо иных вещных прав на конкретный объект недвижимого имущества (сервитута, ипотеки, аренды, ареста имущества и др.). ${ }^{15}$ Обременение активов приводит к усложнению процесса враждебного поглощения, тем самым снижая его риски.

На сегодняшний день наиболее распространёнными способами обременения активов являются передача имущества в доверительное управление и залог. Плюсы передачи имущества в доверительное управление заключаются в том, что это, во-первых, не требует больших финансовых затрат, а, во-вторых, осуществляется в короткие сроки. Имущество, переданное в доверительное управление, становится обособленным, в связи с чем на него перестаёт допускаться обращение по долгам учредителя. Ещё к одному плюсу можно отнести то обстоятельство, что согласно ст. 1017 ГК РФ, недвижимое имущество, переданное в доверительное управление, требует обязательной государственной регистрации, что создаёт для рейдеров дополнительные трудности.

Что касается передачи недвижимого имущества в залог, то этот факт также подлежит государственной регистрации, существенным отличием этого способа является то, что заложенное имущество может продолжать числиться на балансе у залогодателя.

\section{9. Создание эффективной корпоративной структуры в целях распределения финансовых и операционных рисков.}

В ситуации, когда юридическое лицо является собственником основных активов - недвижимости, средств производства и одновременно

14 Фаенсон М.И., Пиманова А.А. Рейдерство (недружественный захват предприятий): практика современной России. М., 2007. C. 67

${ }^{15}$ Федеральный закон от 21 июля 1997 г. N 122-Ф3 «О государственной регистрации прав на недвижимое имущество и сделок с ним» (СПС «Консультант Плюс»). выступает лицом, осуществляющим основную операционную деятельность, вероятность недружественного поглощения максимальна. Поэтому основное внимание следует уделять именно рассредоточению активов, созданию усложненной структуры права собственности на предприятие как имущественный комплекс.

В отдельных случаях эффективным методом защиты может выступать и такой инструмент, как возвратный лизинг ${ }^{16}$ (предприятие-собственник продает соответствующее имущество лизингодателю, который впоследствии передает имущество в пользование бывшему собственнику).

В рамках реализации превентивных защитных мероприятий необходимо также максимально точно рассчитать рыночную стоимость всех активов предприятия. Исходя из данной стоимости, можно понять, какой бюджет поглощения у рейдеров, следовательно, сделать предварительный вывод, какие именно действия будут предприняты последними в целях захвата предприятия.

\section{0. Формирование внутренней службы безопасности.}

При построении надёжной системы превентивной безопасности необходимо учитывать российскую специфику рейдерских захватов. Сложившаяся практика показывает, что зачастую рейдеры осуществляют силовой вход на предприятие, для получения доступа к интересуемым документам или перехвата управления компанией. В связи с этим предприятие должно быть обеспечено надёжной службой внутренней безопасности, способной противостоять незаконному силовому проникновению в компанию.

Актуальность этого направления ярко характеризует пример пермского завода «Привод» - крупнейшего в России производителя турбогенераторов и погружного оборудования для нефтедобычи. В 2005 году группа захвата подделала документы о якобы избрании нового совета директоров и гендиректора и силовым путём прорвалась на территорию завода, однако в этом конкретном случае, рабочие «Привода» смогли отбить здание заводоуправления штурмом, при этом один из них получил тяжелое пулевое ранение в живот.

\footnotetext{
${ }^{16}$ Рыбаков С.A. Возвратный лизинг и отступное как способы вывода активов из-под удара//Корпоративные споры. 2006. N 5. C. 86.
} 


\section{Заключение}

В заключение хочется отметить, что проблема рейдерства для России по-прежнему остаётся актуальной. Не смотря на внесение поправок в УК РФ, направленных на конкретизацию составов преступлений по которым можно привлекать рейдеров к ответственности, на практике количество рейдерских атак остаётся значительным.

Однако, новые поправки в УК РФ всё же дали возможность сотрудникам правоохранительных органов предотвращать рейдерские атаки уже на начальном этапе. После ужесточения законов рейдерские бригады перешли на мелкие предприятия, а суммы ущерба уменьшились. Так, если в позапрошлом году ущерб от рейдеров оценивался в 16 млрд. руб., то в 2011 году лишь в 2 млрд. Однако, проблема рейдерства в России остаётся по-прежнему острой, что наглядно демонстрирует такой факт, как открытие в сентябре, в Пермском Крае музея рейдерства.

Необходимо отметить, что универсальной защиты от рейдерских атак не существует, применение рассмотренных выше превентивных мер лишь резко снижает эффективность успешного осуществления рейдерского захвата. Однако, если эти меры заранее не предпринимать, либо подготавливать непрофессионально, то после того, как атака рейдера началась, возлагать большие надежды на успешную защиту с применением антирейдерских защитных мер не стоит.

Или как гласит древнее латинское изречение $\mathrm{Si}$ vis pacem, para bellum (хочешь мира - готовься к войне).

\section{Библиография:}

1. Астахов П.А. Противодействие рейдерским захватам. М., 2007.
2. Добровольский В.И. Защита корпоративной собственности в арбитражном суде.

3. Клейменов М.П., Федоров А.Ю. Криминальное манипулирование в сфере экономической деятельности: криминологическая характеристика и предупреждение: монография.

4. Рыбаков С.А. Возвратный лизинг и отступное как способы вывода активов из-под удара//Корпоративные споры. 2006. N 5.

5. Фаенсон М.И., Пиманова А.А. Рейдерство (недружественный захват предприятий): практика современной России. М., 2007.

6. Фёдоров А.Ю. Рейдерство и корпоративный шантаж (организационно-правовые меры противодействия). «Волтерс Клувер», 2010 г.

7. http://www.politcom.ru.

8. http://izvestia.ru.

\section{References (transliteration):}

1. Astahov P.A. Protivodejstvie rejderskim zahvatam. M., 2007.

2. Dobrovol'skij V.I. Zashhita korporativnoj sobstvennosti $\mathrm{v}$ arbitrazhnom sude.

3. Klejmenov M.P., Fedorov A.Ju. Kriminal'noe manipulirovanie v sfere jekonomicheskoj dejatel'nosti: kriminologicheskaja harakteristika i preduprezhdenie: monografija.

4. Rybakov S.A. Vozvratnyj lizing i otstupnoe kak sposoby vyvoda aktivov iz-pod udara//Korporativnye spory. 2006. N 5.

5. Faenson M.I., Pimanova A.A. Rejderstvo (nedruzhestvennyj zahvat predprijatij): praktika sovremennoj Rossii. M., 2007.

6. Fjodorov A.Ju. Rejderstvo i korporativnyj shantazh (organizacionno-pravovye mery protivodejstvija). «Volters Kluver», $2010 \mathrm{~g}$. 